\title{
Separation of Azeotropic Mixtures in Closed Batch Distillation Arrangements
}

NTNU

S. Skouras and S. Skogestad

Norwegian University of Science and Technology, Department of Chemical Engineering, Trondheim, Norway

0

SCOPE OF THE PROJECT

How can we separate ternary mixtures in closed batch distillation arrangements?

-What are the batch time (energy) requirements for separating each mixture?

\section{SYSTEMS STUDIED}

i) Zeotropic system: Methano//Ethanol/1-Propanol

ii) Heteroazeotropic system: Methano//Water/l-Butanol (Serafimov's class 1.0-2)

iii) Heteroazeotropic system: Ethyl Acetate/Water/Acetic Acid (Serafimov's class 1.0-1a)

\section{COLUMN ARRANGEMENTS}

a) Conventional multivessel column: The multivessel column combines a batch rectifier and a batch stripper. It has two sections and three vessels. The vapor stream from the stripping section bypasses the middle vessel (Figure 1a)

b) Modified multivessel column: Same characteristics like the conventional multivessel but there is no

c) Cyclic column: A common batch rectifier. The column has one section and two vessels (Figure 1c)
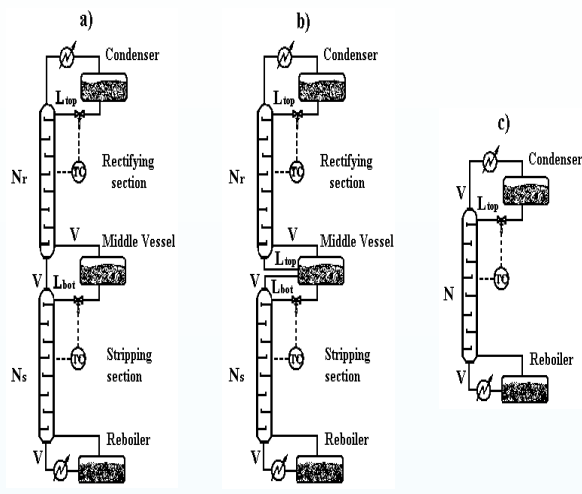

Figure 1: Closed batch distillation arrangements

\section{A) MULTIVESSEL COLUMN}

Conventional: A ternary mixture is separated simultaneously in one closed operation. Three pure components

build-up period is required, istillation step (Figure 3)

Modified: The separation is performed like in the conventional multivessel. In this case the light component is depleted faster in in the middle vessel

\section{B) CYCLIC COLUMN}

The products are separated one at each time in a process resembling to the direct split in continuous columns. For a ternary mixture a sequence of two closed operations (cycles) is needed with an off-cut period in between. During Cycle 1 the light component is accumulated in the top vessel. Cycle 2 is, then,

of the two components left in the still (Figure 4)

For a heteroazeotropic system one of the cycles is necessarily heteroazeotropic distillation step. A build-up priod is require before this heteroazeotropic distillation cycle (Figure 5)
ZEOTROPIC SYSTEM

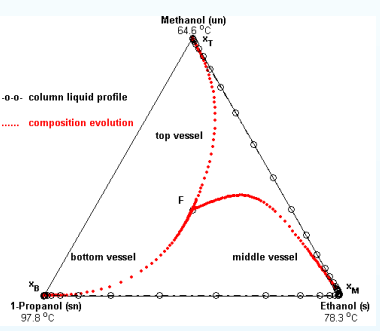

Figure 2: Separation of a zeotropic system in the

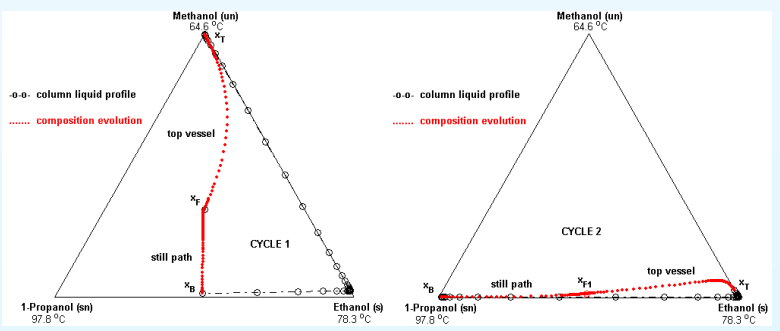

Figure 4: Separation of a zeotropic system in the cyclic column. Two cycles required with an off-cut fraction in between (not shown in the figure)

HETEROAZEOTROPIC SYSTEM

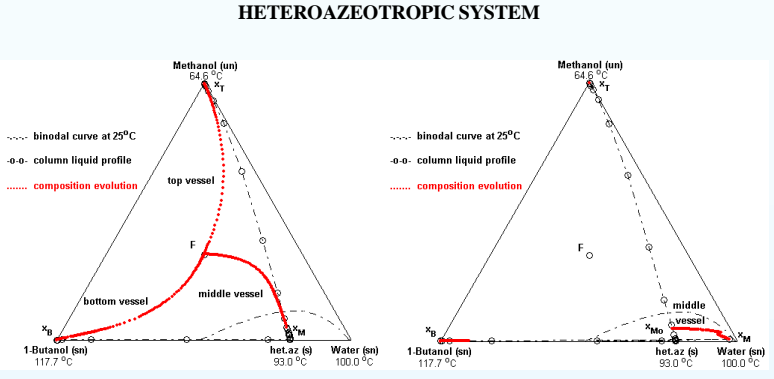

Figure 3: Separation of a heterozeotropic system in the multivessel column. Two steps separation. Initial buildup period (left) follo

\section{TIME CALCULATIONS}

Batch time (energy) requirements and time savings for all column arrangements (basis: conventional multivessel)

\begin{tabular}{cccc}
\hline Zeotropic system & $\begin{array}{c}\text { Conventional multivessel } \\
\text { (with vapor bypass) } \\
3.7 \mathrm{hr}\end{array}$ & $\begin{array}{c}\text { Modified multivessel } \\
\text { (w/o vapor bypass) } \\
-27 \%\end{array}$ & Cyclic column \\
{$[0.99,0.97,0.99]$} & $4.8 \mathrm{hr}$ & $-29 \%$ & $+35 \%$ \\
{$[0.99,0.99,0.99]$} & & & $+19 \%$ \\
\hline Heteroazeotropic systems & & & \\
Class $1.0-2$ & $3.4 \mathrm{hr}$ & $-37 \%$ & $+29 \%$ \\
{$[0.99,0.97,0.99]$} & $4.9 \mathrm{hr}$ & $-33 \%$ & $+40 \%$ \\
{$[0.99,0.98,0.99]$} & & & \\
\hline Class $1.0-1 a$ & $2.8 \mathrm{hr}$ & $-5 \%$ & $+42 \%$ \\
{$[0.97,0.97,0.99]$} & $3.7 \mathrm{hr}$ & $-10 \%$ & $+30 \%$ \\
{$[0.98,0.99,0.99]$} & & &
\end{tabular}

\section{DISCUSSION}

- The cyclic column requires more time than the multivessel column for all separations studied here

- The time advantages of the conventional multivessel column, compared to the cyclic column, become maller as the specification in the middle vessel becomes stricter. The reason is the slow composition dynamics in the middle vessel because of the vapor bypass

-The modified multivessel, without vapor bypass, performs better than the conventional one, for all eparations. This should be attributed to the improved dynamics in the middle vessel. The time advantages of the modified multivessel does not depend on the specifications

- The time advantages of the modified multivessel are small for the third mixture. This is a heteroazeotropic mixture and a decanter is placed in the top of the multivessel column. The process is governed by the dynamics in the decanter and therefore the improved middle vessel dynamics become less important

- The modified multivessel is problematic from the practical point of view for heteroazotropic mixtures. When the decanter is placed in the middle vessel, as for class 1.0-2, we need a vapor stream entering the decanter. When the decanter is placed in the top vessel, as for class 1.0-1a, the time savings become unimportant

\section{CONCLUSIONS}

Separation possibilities in closed batch distillation arrangements were studied for different mixtures. A conventional multivessel column (with a vapor bypass), a modified multivessel (without a vapor bypass) and a cyclic column (rectifier) were studied for the separation of one zeotropic and two heteroazeotropic systems. Batch time (energy) requirements were also provided, based on sim

- All systems studied can be separated in the closed arrangements

- The multivessel column is superior to the cyclic column (rectifier), in terms of batch time (energy) requirements

- The modified multivessel column without vapor bypass is proposed for the separation of zeotropic systems

- The conventional multivessel column with vapor bypass is proposed for the separation of heterogeneous azeotropic systems

\section{REFERENCES}

Furlonge, H.I., Pantelides, C.C., Sørensen, E., (1999). “Optimal Operation of Multivessel Batch
Distillation Columns". AIChE J. 45 (4) 781-801 Hasebe, S., Kurooka, T., Hashimoto, I., (1995), “Comparison of the Separation Performances of a Multi-
Effect Batch Distillation system and a Continuous Distillation System". Proc. IFAC Symp. DYCORD Effect Batch Distillation system and a Continuous

Hilmen E.K., Kiva V.N., Skogestad S., (2002). "Topology of Ternary VLE Diagrams: Elementary Cells",

Meski, G.A., Han, M., Bekiaris, N., Morari, M., (1998). “Optimality for Batch Distillation Configurations". IFAC Symposium DYCOPS-5, Corfu, Greece, 8-19 June 1998, 387-392 Skogestad, S., Wittgens, B., Litto, R., Sørensen, E., (1997). “Multivessel Batch Distillation", AlChe J, 4.

Skouras, S. Skogestad, S., (2003). "Separation of Ternary Heteroazeatropic Mixtures in a Closed
Multivessel Batch Dissillation-Decanter Hybrid" Chem. Eng and Proc, to he published

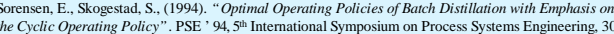
May -3 June 1994, 449-456 